\title{
Functional roles of low calorie sweeteners on gut function
}

A.C. Meyer-Gerspach², B. Wölnerhanssen ${ }^{1,2}$, C. Beglinger ${ }^{1}$

${ }^{1}$ Department of Research, St. Claraspital, Basel, ${ }^{2}$ Department of Biomedicine, University Hospital Basel, and University of Basel, Switzerland

Submitted to: Suppl Physiol\&Behav

Running head: Sweet taste, glucose, fructose, non-caloric sweeteners

\section{Address for correspondence:}

Christoph Beglinger, M.D.

Department of Research

St. Claraspital Basel

$\mathrm{CH}-4016$ Basel, Switzerland

Email: beglinger@tmr.ch 


\section{Abstract}

This short review summarizes the effects of low calorie sweeteners (fructose, nonnutritive low calorie sweeteners) on gut functions focusing on the gut sweet taste receptor system. The effects of these molecules on secretion of gut peptides associated with glycemic homeostasis and appetite regulation is reviewed as well as effects on gastric emptying and glucose absorption.

\section{Introduction}

Obesity is caused by an imbalance between food intake and energy expenditure. Especially the increasing intake of sugar and fat are key factors in the development of obesity. Decades ago it was reported already that too much sugar can be harmful for human health (2) with a clear association between sugar consumption and coronary heart disease. The leading sugar in terms of negative health effects is today the fruit sugar fructose $(3,22)$ mainly in the form of high-fructose corn syrup (HFCS), used in processed food and beverages (22). The development of non-caloric low calorie sweeteners was therefore considered a health benefit because they provide sweet taste without calories or glycemic effects. Six compounds (saccharine, aspartame, acesulfame-K, sucralose, tagatose, and steviol glycoside) are approved by the FDA and generally considered as safe. Research from the last decades suggests, however, that the increased use of non-caloric low calorie sweeteners, especially in the form of soda drinks, can be associated with the development of obesity (for details see review of Pepino) (13); the issue is, however, scientifically controversial. Three main pathways have been proposed to explain the unexpected metabolic disturbance: 1) non-caloric low calorie sweeteners might interact with sweet taste receptors in the gut, which participate in regulating glucose absorption 
and promote insulin release through incretin pathways (3); 2) non-caloric low calorie sweeteners interfere with microbiota, which might induce insulin resistance via different pathways (14); 3) non-caloric low calorie sweeteners could modulate brain responses through the gut-brain axis (12).

In the following short review, the effect of high intensity sweeteners on 1) the gut sweet receptor system and its associated hormone release, 2) on glucose absorption, and 3) on gastric emptying is summarized with a focus on glucose, fructose and non-caloric low calorie sweeteners.

\section{High intensity sweeteners and the sweet taste receptor system}

In the last decade specific receptor- and transporter-systems, which are located in the membrane of specialized epithelial cells such as enteroendocrine cells, have been identified (4). These systems are able to sense ingested nutrients in the gut lumen. The gastrointestinal gustatory system consists of a neural-epithelial machinery linking the sensory epithelial cells of the gut to the first gustatory relay center in the brain (4). The system contains neuroactive peptides such as glucagon like peptide-1 (GLP-1), peptide tyrosine tyrosine (PYY) and cholecystokinin (CCK); these peptides are secreted upon specific nutrient stimulation. G protein-coupled receptors and solute transporters expressed on the apical end of taste receptor cells function as the receptors for these luminal nutrients and induce the release of specific signaling molecules such as CCK, GLP-1 and PYY (5). The main ligands for these receptor- and transporter- systems in the gut are the three macronutrients (proteins, fats and carbohydrates) as well as their breakdown products, including amino acids, long-chain and short-chain fatty acids and monosaccharides.

The discovery of chemosensory cells in the gastrointestinal tract has triggered studies on the physiological role of these receptors in the gut $(4,8,11)$. These 
receptors can sense at least five basic tastes (sweet, umami, bitter, sour and salty) similar to the tongue and serve as interface between the nutrients in the lumen and the human body: the gut tastes what we eat.

Sweet taste receptor. The sensation of sweet taste is mediated by the heterodimer receptor T1R2/T1R3 (sweet taste receptor). Glucose and low calorie sweeteners bind to $T 1 R 2 / T 1 R 3$ that is coupled to the heterotrimeric G-protein ( $\alpha$-gustducin, GB3 and $G y 13)(7,11,21)$. Through activation, the G-protein subunits separate to $\alpha$ gustducin and $\beta y$-unit (GB3-Gy13); the latter activates an intracellular cascade, which results in the release of $\mathrm{Ca}^{2+}$ from internal stores.

The expression of signaling components of the sweet taste receptor outside the tongue was first described by Höfer et al. (6). He reported that a-gustducin is expressed in the stomach, duodenum and pancreatic duct of rats. Later it was shown in humans that T1R3 and $\alpha$-gustducin is expressed in the colon and that $\alpha$-gustducin is localized in enteroendocrine L- and K-cells $(5,15)$. The observed co-localization of a-gustducin with PYY and GLP-1 in human colonic cells confirmed these findings (8). In a subset of CCK cells, $\alpha$-gustducin and T1R2 were co-expressed suggesting that these cells can respond to sweet compounds (16). The expression of the different taste-signaling elements in enteroendocrine cells of the human gut was confirmed by work carried out in different laboratories $(5,7,15,18)$.

The role of sweet taste receptors in incretin release. Jang et al. showed that plasma GLP-1 levels following glucose gavage were reduced in $\alpha$-gustducin $\left(\alpha-g u s t^{-}\right)$or T1R3 $\left(T 1 R 3^{--}\right)$knockout mice compared to wild-type mice leading to impaired insulin release and elevated blood glucose levels (7). These results were confirmed in $\mathrm{T} 1 \mathrm{R}^{/-}$knockout mice with impaired glucose and insulin homeostasis during oral glucose challenges (5). Based on these data, we performed experiments in humans 
to determine the functional importance of sweet taste receptors in glucose-stimulated secretions of GLP-1, PYY and CCK (18). Glucose was a potent stimulus for GLP-1 and PYY secretion, whereas equisweet fructose was markedly less effective. To test whether the glucose effect was mediated via the sweet taste receptor, we used lactisole (a competitive inhibitor of the sweet taste receptor subunit T1R3) to block the sweet taste receptors in the gut. Lactisole significantly attenuated the glucosestimulated secretion of GLP-1 and PYY. In contrast, CCK secretion was unaffected by lactisole, indicating that glucose-induced CCK secretion is not mediated by the sweet taste receptor and that other glucose-sensing receptors must be involved. More important, lactisole had no effect on mixed liquid meal-stimulated GI peptide secretion (18). The liquid meal consisted of glucose, proteins, fats, and other complex carbohydrates. The lack of effect of lactisole with a mixed meal stimulation suggests that these nutrients induce the release of satiation peptides via other mechanisms and these mechanisms seem to outweigh the effect of sweet receptor blockade. Long-chain fatty acids, apart from glucose, are also potent luminal secretagogues for GLP-1 release (1). Thus, the fast response to glucose is based on sensing and activation of the sweet receptor system, whereas the effects of a mixed meal are also mediated by breakdown products of lipids and perhaps proteins.

Role of sweet taste receptors in glucose absorption. Glucose is absorbed from the gut via the sodium-dependent glucose co-transporter (SGLT-1) on the apical membrane and the glucose transporter 2 (GLUT2) on the basolateral membrane of the enterocyte (8). Sweet taste receptor expression in the GI tract regulates the transport of glucose (17). The Adelaide group (24) has documented that sweet taste receptor expression is unchanged by acute variations of glycemia, both in healthy subjects and in patients with type 2 diabetes mellitus, but increases upon exposure to luminal glucose in euglycemia. Increased expression of the sweet taste receptor 
system in the gut during euglycemia induces increased glucose absorption, both in healthy persons and type 2 diabetic subjects. In contrast, sweet taste receptor transcript levels decreased during hyperglycemia in healthy subjects in response to duodenal glucose perfusion, but increased in type 2 diabetic subjects suggesting that a disturbed regulation of the sweet taste receptor system can aggravate postprandial hyperglycemia.

Role of sweet taste receptors in artificial sweetener sensing. Both, non-nutritive (artificial) and caloric sweeteners bind to the oral sweet taste receptors resulting in the conscious sensation of sweetness. It was therefore a small step to hypothesize that low calorie sweeteners could bind to the sweet taste receptors in the gut. This possibility has been explored in multiple models with inconsistent results.

In vitro studies with the human L-cell line, $\mathrm{NCl}-\mathrm{H} 716$, as well as with the mouse GLUTag cell line, documented secretion of GLP-1 induced by sucralose (artificial sweetener); the effect was blocked by the sweet taste receptor antagonist lactisole and by siRNA targeting $\alpha$-gustducin $(7,10)$. These results are, however, controversial and could not be confirmed in two further studies (reviewed by Brown et al. (3)). In healthy humans administration of oral sucralose or intragastric administration of sucralose, aspartame, or acesulfame-K failed to stimulate GLP-1, PYY, or GIP secretion $(2,19)$. Similar findings were obtained in a study in which sucralose neither stimulated GLP-1 nor PYY release in fasted subjects. Six studies in humans have been published: none of them detected effects of non-nutritive, low calorie sweeteners on gut hormone release or glucose absorption (for details see (2)). In one study the effect of non-nutritive low calorie sweeteners in a commercially available diet soda on GLP-1 secretion in combination with caloric sugars was investigated; the authors reported that the plasma GLP-1 area under the curve after glucose ingestion was significantly higher after diet soda compared with carbonated 
water. The results would suggest that diet soda (presumably via the non-nutritive sweeteners) enhances glucose-stimulated GLP-1 secretion (2). It is not clear from the experiment whether this effect was mediated via sweet-taste receptors, as diet soda contains many other ingredients apart form non-nutritive sweeteners. More important, the results could not be confirmed in another study (23). Taken together, these data support the notion that low calorie sweeteners in isolation, are not a sufficient stimulus for sweet taste receptors to induce Gl peptide secretion in humans. Whether higher doses of low calorie sweeteners, as used in in vitro experiments, would stimulate incretin release is not known but the information would be of little practical relevance.

Effect of sweeteners on gastric emptying. Intestinal exposure of the gut to glucose stimulates the release of GLP-1, which subsequently slows gastric emptying. This effect is, at least in part, mediated by the sweet taste receptor system. Gastric emptying of glucose is dependent on the osmolality of the ingested glucose drink. Increasing loads of glucose induce a load dependent slowing of gastric emptying. Equisweet solutions of fructose, aspartame, and saccharin had no effect on gastric emptying rates, but glucose slowed gastric emptying (10). Fructose when given intravenously slows gastric emptying; the magnitude is similar to an identical intravenous glucose load (20). A limitation in the literature is that studies with sweeteners (glucose, fructose, low calorie sweeteners) are difficult to compare as 1) different methods are used to assess gastric emptying, 2) different test drinks are given (should equisweet or equimolar test drinks be used?), and 3) only a limited number of subjects are tested in a given protocol. Thus, the available information suggests that glucose and fructose have similar decelerating effects on gastric emptying, whereas low calorie sweeteners have no effect. 


\section{Summary and Conclusion}

The discovery of the sweet taste receptor system in the gut has led to new concepts linking nutrient sensing to physiological mechanisms. Glucose and, to a lesser degree, fructose stimulate incretin release and the effect seems to be mediated by the sweet taste receptor. The ability of low calorie sweeteners to regulate digestive functions and glucose homeostasis is equivocal in the literature with apparent discrepancies between animal research and human studies. In humans, low calorie sweeteners have failed to stimulate incretin release or gastric emptying, which does not exclude an effect on other digestive functions. We infer from these observations that low calorie sweeteners have little if any effect on gastric emptying and incretin release in humans. We cannot exclude interactions of low calorie sweeteners with the microbiome triggering indirect effects. Based on these data, it is not possible to draw firm conclusions in relation to the prevention of obesity. The developing story is complex, but has an important influence on taste research. The available data suggest that some complex challenges have to be sorted out.

\section{Acknowledgments}

This research is supported by a grant of the Swiss National Science Foundation (Grant No. 320030-132960/1) and the affiliated Marie Heim-Vögtlin Foundation (Grant No. NMS1793). 
Table: Effect of glucose, fructose and low calorie sweeteners on GLP-1, PYY release and gastric emptying

\begin{tabular}{|l|l|l|l|l|l|}
\hline Parameter & Glucose & Fructose & Sucralose & Ace-K & Aspartame \\
\hline $\begin{array}{l}\text { GLP-1 } \\
\text { release }\end{array}$ & $\begin{array}{l}\text { Potent } \\
\text { secretagogue }\end{array}$ & $\begin{array}{l}\text { Poor } \\
\text { secretagogue }\end{array}$ & No effect & No effect & No effect \\
\hline GIP release & $\begin{array}{l}\text { Potent } \\
\text { secretagogue }\end{array}$ & $\begin{array}{l}\text { Poor } \\
\text { secretagogue }\end{array}$ & No effect & Not tested & Not tested \\
\hline $\begin{array}{l}\text { PYY } \\
\text { release }\end{array}$ & $\begin{array}{l}\text { Poor } \\
\text { secretagogue }\end{array}$ & $\begin{array}{l}\text { Poor } \\
\text { secretagogue }\end{array}$ & No effect & No effect & No effect \\
\hline $\begin{array}{l}\text { Gastric } \\
\text { emptying }\end{array}$ & $\begin{array}{l}\text { Load } \\
\text { dependent } \\
\text { slow down }\end{array}$ & $\begin{array}{l}\text { Load } \\
\text { dependent } \\
\text { slow down }\end{array}$ & No effect & No effect & No effect \\
\hline
\end{tabular}

References 3, 4, 5, 19, 23 


\section{References}

1. S. Beglinger, J. Drewe, J. Schirra, B. Goke, M. D'Amato, C. Beglinger

Role of fat hydrolysis in regulating glucagon-like peptide-1 secretion.

J Clin Endocrinol Metab 95 (2010), pp. 879-886.

2. G.A. Bray

Obesity increases risk for diabetes.

Int J Obes Relat Metab Disord Suppl 4 (1992) pp. S13-S17.

3. R.J. Brown, K.I. Rother

Non-nutritive sweeteners and their role in the gastrointestinal tract.

J Clin Endocrinol Metab 97 (2012) pp. 2597-2605.

4. M.V. Burke, D.M. Small

Physiological mechanisms by which non-nutritive sweeteners may impct body weight and metabolism.

Physiol Behav. 152 (2015) pp.381-388.

\section{I. Depoortere}

Taste receptors of the gut: emerging roles in health and disease.

Gut. 63 (2014) pp. 179-190.

6. A.C. Gerspach, R.E. Steinert, L. Schonenberger, A. Graber-Maier, C. Beglinger The role of the gut sweet taste receptor in regulating GLP-1, PYY, and CCK release in humans.

Am J Physiol Endocrinol Metab. 301 (2011) pp. E317-325.

\section{D. Hofer, B. Puschel, D. Drenckhahn}

Taste receptor-like cells in the rat gut identified by expression of alpha-gustducin. Proc Natl Acad Sci U S A. 93 (1996) pp. 6631-6634.

8. H.J. Jang, Z. Kokrashvili, M.J. Theodorakis, O.D. Carlson, B.J. Kim, J. Zhou, et al. Gut-expressed gustducin and taste receptors regulate secretion of glucagon 
like peptide-1.

Proc Natl Acad Sci U S A 104 (2007) pp. 15069-15074.

9. G.L. Kellett, E. Brot-Laroche, O.J. Mace, A. Leturque

Sugar absorption in the intestine: the role of GLUT2.

Annu Rev Nutr (28) 2008 pp. 35-54.

10. T.J. Little, N. Gupta, R.M. Case, D.G. Thompson, J.T. McLaughlin

Sweetness and bitterness taste meals per se does not mediate gastric emptying in humans.

Am J Physiol Regul Integr Comp Physiol. 297 (2009) pp. R632-R639.

11. R.F. Margolskee, J. Dyer, Z. Kokrashvili, K.S. Salmon, E. llegems, K. Daly, et al. T1R3 and gustducin in gut sense sugars to regulate expression of $\mathrm{Na+-glucose}$ cotransporter 1.

Proc Natl Acad Sci U S A. 104 (2007) pp. 15075-15080.

12. R.D. Mattes, B.M. Popkin

Nonnutritive sweetener consumption in humans: effects on appetite and food intake and their putative mechanisms.

Am J Clin Nutr. 89 (2009) pp. 1-14.

13. M.Y. Pepino

Metabolic effects of non-nutritive sweeteners.

Physiol Behav. 152 (2015) pp. 450-455.

14. M.Y. Pepino, C. Bourne

Non-nutritive sweeteners, energy balance and glucose homeostasis.

Curr Opin Clin Nutr Metab Care. 14 (2011) pp. 391-395.

15. N. Rozengurt, S.V. Wu, M.C. Chen, C. Huang, C. Sternini, E. Rozengurt Colocalization of the alpha-subunit of gustducin with PYY and GLP-1 in L cells of human colon.

Am J Physiol Gastrointest Liver Physiol. 291 (2006) pp. G792-802. 
16. Shen T, Kaya N, Zhao FL, Lu SG, Cao Y, Herness S.

Co-expression patterns of the neuropeptides vasoactive intestinal peptide and cholecystokinin with the transduction molecules $\alpha$-gustducin and T1R2 in rat taste receptor cells.

Neuroscience 2005;130(1):229-238

17. S. P. Shirazi-Beechey, A.W. Moran, D.J. Batchelor, K. Daly, M. Al-Rammahi Glucose sensing and signalling; regulation of intestinal glucose transport.

Proc Nutr Soc 70 (2011) pp. 185-193.

18. R.E. Steinert, A.C. Gerspach, H. Gutmann, L. Asarian, J. Drewe, C. Beglinger The functional involvement of gut-expressed sweet taste receptors in glucose stimulated secretion of glucagon-like peptide-1 (GLP-1) and peptide YY (PYY).

Clin Nutr 30 (2011) pp. 524-532.

19. R.E. Steinert, F. Frey, A. Topfer, J. Drewe, C. Beglinger

Effects of carbohydrate sugars and low calorie sweeteners on appetite and the secretion

of gastrointestinal satiety peptides.

Br J Nutr 105 (2011) pp. 1-9.

20. Stevens JE, Doran S, Russo A, O'Donovan D, Feinle-Bisset C, Rayner CK, Horowitz, M, Jones KL.

Effects of intravenous fructose on gastric emptying and antropyloroduodenal motility in health subjects.

Am J Physiol Gastrointest Liver Physiol. 2009;297(6):G1274-G1280.

21. Tolhurst G, Reimann F, Gribble FM

Intestinal sensing of nutrients.

Handb Exp Pharmacol 2012:309-335.

22. White JS.

Straight talk about high-fructose corn syrup: what it is and what it ain't. Am J Clin Nutr. 2008;88(6):1716S-1721S 
23. Wu T, Zhao BR, Bound MJ, Checklin HL, Bellon M, Little TJ, Young RL, Jones KL, Horowitz M, Rayner CK.

Effects of different sweet preloads on incretin hormone secretion, gastric emptying, and postprandial glycemia in healthy humans.

Am J Clin Nutr. 2012;95:78-83

24. Young RL, Chia B, Isaacs NJ, Ma J, Khoo J, Wu T, Horowitz M, Rayner CK. Disordered control of intestinal sweet taste receptor expression and glucose absorption in type 2 diabetes.

Diabetes 2013;62(10):3532-3541. 